\title{
09.1
}

\section{Катодолюминесценция пленок ZnO на ромбоэдрической плоскости сапфира с буферным слоем золота}

\author{
() А.Э. Муслимов ${ }^{1}$, А.П. Тарасов ${ }^{2,3}$, А.М. Исмаилов ${ }^{4}$, В.М. Каневский ${ }^{1}$ \\ ${ }^{1}$ Федеральный научно-исследовательский центр „Кристаллография и фотоника“ РАН, Москва, Россия \\ 2 Московский физико-технический институт (Национальный исследовательский университет), Долгопрудный, \\ Московская обл., Россия \\ ${ }^{3}$ Московский областной научно-исследовательский клинический институт им. М.Ф. Владимирского, Москва, Россия \\ ${ }^{4}$ Дагестанский государственный университет, Махачкала, Россия \\ E-mail: amuslimov@mail.ru
}

Поступило в Редакцию 8 июля 2020г.

В окончательной редакции 8 июля 2020 г.

Принято к публикации 12 сентября 2020 г.

\begin{abstract}
Исследованы люминесцентные свойства пленок $\mathrm{ZnO}$ на ромбоэдрической плоскости сапфира с буферным слоем наноостровков золота. В спектре люминесценции обнаружен набор осцилляций, являющийся следствием классической интерференции на тонкой пленке. Набор осцилляций может быть представлен в виде штрихкода, в котором каждый штрих соответствует длине волны заданной осцилляции, а толщина штриха ее интенсивности. Высокая воспроизводимость и простота изготовления подобных тонкопленочных структур на основе ZnO с учетом чувствительности интерференционных явлений на таких структурах к внешней среде создают перспективы их применения в качестве элементов различных хемо- и биосенсоров.
\end{abstract}

Ключевые слова: $\mathrm{ZnO}$, сапфир, золото, интерференция, люминесценция.

DOI: 10.21883/PJTF.2020.24.50421.18459

В последнее время оксид цинка $(\mathrm{ZnO})$, который традиционно являлся одним из основных материалов пьезоэлектроники, фотоники, уверенно захватывает свою нишу в биомедицинских технологиях [1-4]. Этому способствует биосовместимость, бактерицидность, иммуномодулирующие и другие свойства $\mathrm{ZnO}$. Анализ литературы демонстрирует, что оптимальной конфигурацией ZnO для биомедицинских приложений являются наночастицы. В то же время наименее затратными и воспроизводимыми являются тонкопленочные технологии. Недавно [5] было предложено использовать специфические свойства планарных структур на основе нанопористого оксида алюминия в качестве метки в биологических системах. Суть инновации заключается в представлении набора осцилляций в спектре люминесценции нанопористого оксида алюминия в виде штрихкода. Каждый штрих соответствует длине волны заданной осцилляции, а толщина штриха - ее интенсивности. Аналогичные особенности люминесцентных свойств оксида цинка также могли бы найти применение, однако в настоящее время отсутствует технология создания нанопористого $\mathrm{ZnO}$. Тем не менее, учитывая специфику роста оксида цинка на различных подложках, можно, создать столбчатую микроструктуру оксида цинка, поддерживающую распространение света между ее поверхностями. Такая система позволит промодулировать спектр излучения с формированием набора осцилляций. Традиционно для усиления эффективности торцы микрорезонатора покрывают высокоотражающей металлической пленкой, например пленкой золота. Рассмотренную схему можно реализовать на подложках сапфира ромбоэдрической ориентации с использованием „наноостровков““ золота в качестве буферного слоя. Одновременно с этим центры окраски в подложках сапфира могут являться источником излучения. Известно [6,7], что на ромбоэдрической $(R)$ плоскости сапфира благодаря структурногеометрическому подобию решеток традиционно растет пленка (110) ZnO с осью [0001] кристаллитов, расположенной параллельно подложке. С другой стороны, для пленок с вюрцитной структурой наблюдается сильная тенденция к текстурированию вдоль оси [0001], направленной перпендикулярно подложке [8]. Ранее нами [9] было показано, что использование буферных слоев золота способствует текстурированию пленки $\mathrm{ZnO}$ вдоль [0001], а в случае применения базисных подложек сапфира даже наблюдается эпитаксиальный рост. Объединяя полученные ранее результаты, можно резюмировать, что для формирования столбчатой микроструктуры пленки $\mathrm{ZnO}$ с ярко выраженными границами оптимальным является использование $R$-сапфира с подслоем золота в виде наноостровков. Подслой золота в свою очередь будет выполнять функцию высокоотражающего покрытия. Исследованию особенностей спектра люминесценции системы $\mathrm{ZnO} / \mathrm{Au} / R$-сапфир посвящена настоящая работа.

В качестве подложек использовалась ромбоэдрическая плоскость сапфира, обработанная химико-механическим способом до значений шероховатости порядка $0.2 \mathrm{~nm}$. Пленки $\mathrm{ZnO}$ осаждались методом магнетронного распыления. Предварительно на подложку методом термического осаждения наносился слой золота толщиной порядка $25 \mathrm{~nm}$. Слой золота подбирался в соответствии с расчетами, представленными в [10], и необходимостью 

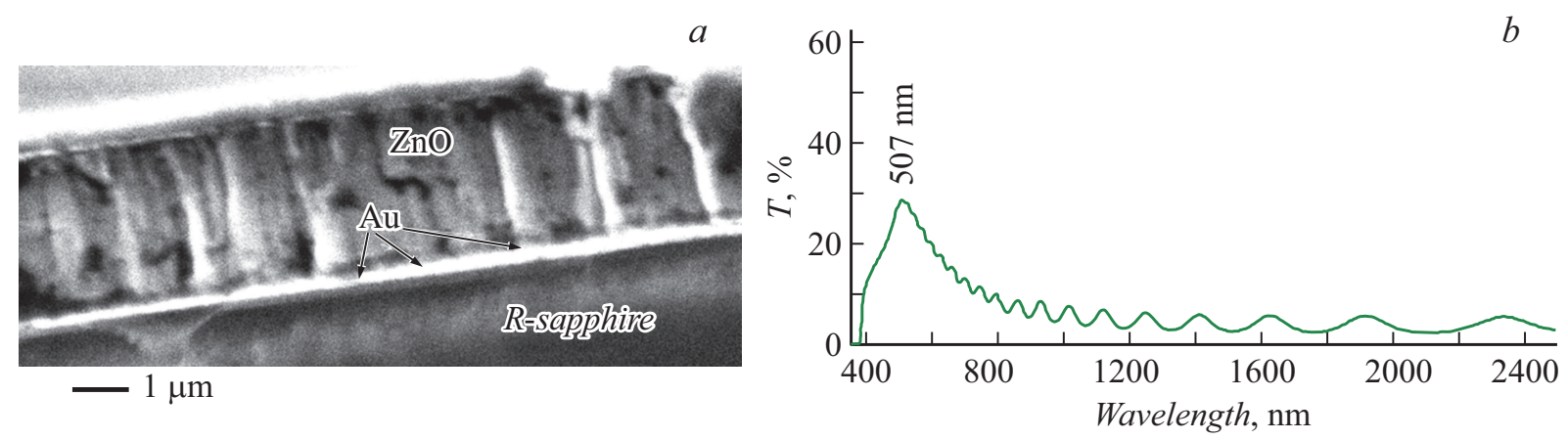

Рис. 1. Электронно-микроскопическое изображение среза $(a)$ и спектр пропускания $(b)$ образца пленки ZnO на ромбоэдрической плоскости сапфира с подслоем наноостровков золота.

реализации прямого механизма роста пар-кристалл без формирования микрокристаллов $\mathrm{ZnO}$ по механизму пар-жидкость-кристалл [11].

Далее подложка прогревалась при температуре $730^{\circ} \mathrm{C}$ для осуществления этапа коалесценции осажденных атомов золота с образованием наноостровков. На следующем этапе наносилась пленка $\mathrm{ZnO}$ при температуре $810^{\circ} \mathrm{C}$ в атмосфере кислорода при давлении $1.33 \mathrm{~Pa}$. Скорость роста пленок составляла $\sim 2 \mathrm{~nm} \cdot \mathrm{s}^{-1}$.

Для структурных исследований пленки использовалась электронная дифракция „на отражение“ (горизонтальный электронограф, ускоряющее напряжение $75 \mathrm{kV}$ ). Исследование спектров излучения осуществлялось возбуждением катодолюминесценции (КЛ) в пленках скользящим электронным пучком электронографа. Микроскопические исследования поперечного скола образца проводились на растровом электронном микроскопе Jeol Neoscope 2 (JCM-6000).

Пленка оксида цинка по данным дифракции быстрых электронов текстурирована вдоль оси $c$ [0001]. Микроскопическое изображение среза пленки (рис. 1,a) демонстрирует ее столбчатую микроструктуру. Толщина пленки порядка $3 \mu \mathrm{m}$. У основания пленки наблюдаются наночастицы золота с размерами порядка 250-300 nm.

В спектре пропускания выделяется максимум в области $507 \mathrm{~nm}$ (рис. 1,b). В целом образец демонстрирует нехарактерное для пленок $\mathrm{ZnO}$ на сапфире низкое пропускание в широком спектральном диапазоне. Облучение электронами образца при ускоряющем напряжении $70 \mathrm{kV}$ вызывало алое свечение (рис. 2,a). В спектре люминесценции (рис. 2,b) наблюдались две полосы: узкая в области 385-392 nm и широкая в области 550-1000 nm. Положение и форма полос КЛ зависели от режима возбуждения. На спектральной зависимости КЛ, особенно в длинноволновой области, наблюдались ярко выраженные осцилляции.

Ранее во вводной части обсуждалось, что такие факторы, как присутствие подслоя золота, тенденция к текстурированию вдоль направления [0001], приводят к формированию пленки $\mathrm{ZnO}$ со столбчатой микроструктурой с ярко выраженными границами между элементами на $R$ - сапфире. В соответствии с результатами, полученными в [10], можно оценить усредненный диаметр наноостровков золота $\sim 250 \mathrm{~nm}$, что находится в хорошем согласии с их микроскопическим изображением (рис. 1,a). Отсутствие процесса неоднородного разрастания кристаллитов, характерного для эпитаксиального роста, позволяет получить отдельные элементы микроструктуры $\mathrm{ZnO}$, близкие по высоте, что увеличивает общую плоскостность поверхности пленки. Спектр пропускания (рис. $1, b$ ) свидетельствует об преимущественном поглощении излучения в наноостровках золота. Так, пик в области $507 \mathrm{~nm}$ связан с появлением межзонных переходов в золоте в более длинноволновой области [10]. Узкий пик в области 385-392 nm (рис. 2,b) связан с краевой люминесценцией в ZnO. Следует отметить, что при минимальном воздействии электронного пучка пик располагается в области $385 \mathrm{~nm}$, а при увеличении времени воздействия (до $3 \mathrm{~min}$ ) или фокусировке пучка электронов смешается в область 390-392 nm. Вероятно, это связано с локальным нагревом и уменьшением ширины запрещенной зоны $\mathrm{ZnO}$, которая описывается моделью Варшни [12].

Широкая полоса катодолюминесценции в длинноволновой области традиционно связана с примесью трехвалентного титана в сапфире [13]. При этом можно наблюдать ее подавление при фокусировке пучка. Известно, что температурное гашение люминесценции является активационным процессом. При фокусировке пучка происходит локальный нагрев, который приводит к подавлению люминесценции. Имеются данные [14], которые показывают, что уже при температуре порядка $300^{\circ} \mathrm{C}$ происходит существенное гашение полос люминесценции $\mathrm{Ti}^{3+}$.

Осцилляционный характер спектра КЛ образца является следствием классической интерференции на тонкой пленке. Это подтверждается характерным смещением интерференционных полос при наклоне образца относительно направления на фотодетектор, а также оценкой толщины пленки $d$ по следующей формуле, справедливой при нормальном расположении фотодетек- 

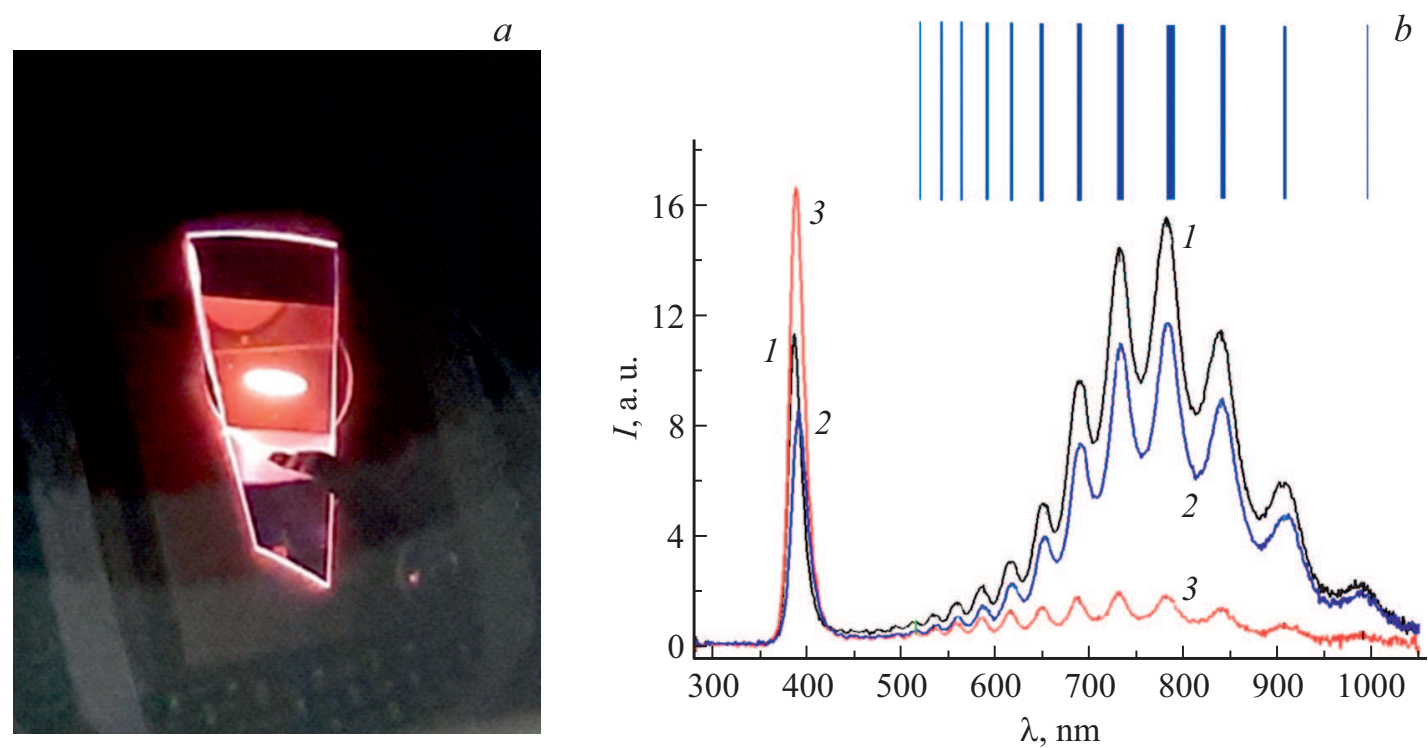

Рис. 2. Оптическое изображение образца в процессе излучения при ускоряющем напряжении $70 \mathrm{kV}(a)$ и спектры излучения $($ КЛ $)$ в различных режимах возбуждения $(b)$ образца пленки $\mathrm{ZnO}$ на $R$-сапфире с подслоем наноостровков золота. $1-$ время облучения $10 \mathrm{~s} ; 2$ - время облучения $3 \mathrm{~min} ; 3$ - время облучения $10 \mathrm{~s}$, фокусированный пучок электронов. На вставке набор осцилляций представлен в виде штрихкода, каждый штрих соответствует длине волны заданной осцилляции, а толщина штриха ее интенсивности.

тора относительно возбуждаемой на образце области:

$$
d=\frac{\lambda^{2}}{2 \Delta \lambda\left(n(\lambda)-\lambda \frac{\operatorname{dn}(\lambda)}{d \lambda}\right)},
$$

где $\Delta \lambda$ - расстояние между максимумами полос, $n(\lambda)-$ показатель преломления на длине волны $\lambda$. Используя $n(\lambda)$ из литературы (например, $[15,16])$, при оценке по формуле (1) получаем $d \sim 2.7-2.9 \mu \mathrm{m}$ в зависимости от используемого $n(\lambda)$, что соответствует результатам микроскопических исследований.

В рассматриваемом случае примечательно то, что источник интерферирующего света находится не в самой пленке $\mathrm{ZnO}$ [17], а в сапфировой подложке; таким образом, интерференция наблюдается в геометрии „на прохождение“ и захватывает широкий спектральный диапазон.

Интерференционные полосы отчетливо выражены и заметны даже в спектральной области краевого излучения $\mathrm{ZnO}$. Это указывает на высокое качество выращенной пленки, столбчатая структура которой поддерживает распространение света между ее поверхностями.

Таким образом, в работе исследованы люминесцентные свойства пленок $\mathrm{ZnO}$ на ромбоэдрической плоскости сапфира с буферным слоем наноостровков золота. Микроскопическое изображение среза пленки $\mathrm{ZnO}$ демонстрирует ее столбчатую микроструктуру. Спектр пропускания с характерным максимумом в области $507 \mathrm{~nm}$ свидетельствует о преимущественном поглощении излучения в наноостровках золота. В спектре люминесценции образца обнаружен набор осцилляций, являющийся следствием классической интерференции на тонкой пленке. Набор осцилляций может быть представлен в виде штрихкода (вставка на рис. $2, b$ ), в котором каждый штрих соответствует длине волны заданной осцилляции, а толщина штриха - ее интенсивности. Высокая воспроизводимость и простота изготовления подобных тонкопленочных структур на основе $\mathrm{ZnO}$ с учетом чувствительности интерференционных явлений на таких структурах к внешней среде создают перспективы их применения в качестве элементов различных хемо- и биосенсоров.

\section{Финансирование работы}

Работа выполнена с использованием оборудования ЦКП ФНИЦ „Кристаллография и фотоника“ в рамках выполнения работ по государственным заданиям ФНИЦ „Кристаллография и фотоника“ $\mathrm{PAH,} \mathrm{а} \mathrm{также}$ при поддержке Российского фонда фундаментальных исследований (грант № 18-29-12099 мк).

\section{Конфликт интересов}

Авторы заявляют, что у них нет конфликта интересов.

\section{Список литературы}

[1] Krishnakumar T., Jayaprakash R., Pinna N., Singh V.N., Mehta B.R., Phani A.R. // Mater. Lett. 2009. V. 63. N 2. P. 242-245.

[2] Padmavathy N., Vijayaraghavan R. // Sci. Technol. Adv. Mater. 2008. V. 9. N 3. P. 035004. 
[3] Darroudi M., Sabouri Z., Oskuee R.K., Khorsand Zak A., Kargar H., Abd Hamid M.H.N. // Ceram. Int. 2014. V. 40. N 3. P. $4827-4831$.

[4] Huang Z., Zheng X., Yan D., Yin G., Liao X., Kang Y., Yao Y., Huang D., Hao B. // Langmuir. 2008. V. 24. N 8. P. 4140 4144.

[5] Santos A., Balderrama V.S., Alba M., Formentín P., FerréBorrull J., Pallarés J., Marsal L.F. // Adv. Mater. 2012. V. 24. N 8. P. $1050-1054$.

[6] Муслимов А.Э., Исмаилов А.М., Бабаев В.А., Каневский B.M. // Кристаллография. 2019. Т. 64. N 5. С. 790-795.

[7] Муслимов А.Э., Исмаилов А.М., Бабаев В.А., Каневский B.M. // Поверхность. 2019. № 12. С. 61-65.

[8] Podlogar M., Richardson J.J., Vengust D., Daneu N., Samardžija Z., Bernik S., Rečnik A. // Adv. Funct. Mater. 2012. V. 22. N 15. P. 3136-3145.

[9] Власов В.П., Буташин А.В., Каневский В.М., Муслимов А.Э., Ли Л.Е., Ракова Е.В., Бабаев В.А., Исмаилов А.М. // Кристаллография. 2014. Т. 59. № 5. С. 806-808.

[10] Ушаков Н.М., Васильков М.Ю., Федоров Ф.С. // Письма в ЖТФ. 2017. Т. 43. В. 14. C. 26-33.

[11] Li S.Y., Lee C.Y., Tseng T.Y. // J. Cryst. Growth. 2003. V. 247. N 3-4. P. 357-362.

[12] Varshni Y.P. // Physica. 1967. V. 34. N 1. P. 149-154.

[13] Burton H., Debardelaben C., Amir W., Planchon T.A. // Opt. Express. 2017. V. 25. N 6. P. 6954-6962.

[14] Drabik J., Cichy B., Marciniak L. // J. Phys. Chem. C. 2018. V. 122. N 26. P. $14928-14936$.

[15] Liu J., Lee S., Ahn T.H., Park J.Y., Koh K.H., Park K.H. // Appl. Phys. Lett. 2008. V. 92. N 26. P. 263102.

[16] Morkoc H., Ozgur U. Zinc oxide: fundamentals, materials and device technology. John Wiley \& Sons, 2008. 488 p.

[17] Wang Y.G., Ohashi N., Ryoken H., Haneda H. // J. Appl. Phys. 2006. V. 100. N 11. P. 114917. 